\title{
Tall cell papillary thyroid carcinoma: new diagnostic criteria and mutations in BRAF and TERT
}

\author{
Matthias S Dettmer, Anja Schmitt, Hans Steinert ${ }^{1}$, David Capper ${ }^{2}$, Holger Moch ${ }^{3}$, \\ Paul Komminoth ${ }^{4}$ and Aurel Perren \\ Institute of Pathology, University of Bern, Murtenstrasse 31, 3010 Bern, Switzerland \\ ${ }^{1}$ Division of Nuclear Medicine, University Hospital Zurich, Zurich, Switzerland \\ ${ }^{2}$ Department of Neuropathology, Institute of Pathology, German Cancer Research Center (DKFZ), \\ Ruprecht-Karls University, and Clinical Cooperation Unit Neuropathology, Heidelberg, Germany \\ ${ }^{3}$ Institute of Surgical Pathology, University Hospital Zurich, Zurich, Switzerland \\ ${ }^{4}$ Institute of Surgical Pathology, Triemlispital, Zürich, Switzerland
}

\author{
Correspondence \\ should be addressed \\ to M S Dettmer \\ Email \\ dettmerms@gmail.com or \\ matthias.dettmer@ \\ pathology.unibe.ch
}

\begin{abstract}
The tall cell (TC) variant of papillary thyroid carcinoma (PTC) has an unfavorable prognosis. The diagnostic criteria remain inconsistent, and the role of a minor TC component is unclear. Molecular diagnostic markers are not available; however, there are two potential candidates: BRAF V600E and telomerase reverse transcriptase (TERT) promoter mutations. Using a novel approach, we enriched a collective with PTCs that harbored an adverse outcome, which overcame the limited statistical power of most studies. This enabled us to review 125 PTC patients, 57 of which had an adverse outcome. The proportion of TCs that constituted a poor prognosis was assessed. All of the tumors underwent sequencing for TERT promoter and BRAF V6O0E mutational status and were stained with an antibody to detect the BRAF V600E mutation. A $10 \%$ cutoff for TCs was significantly associated with advanced tumor stage and lymph node metastasis. Multivariate analysis showed that TCs above $10 \%$ were the only significant factor for overall, tumor-specific, and relapse-free survival. Seven percent of the cases had a TERT promoter mutation, whereas $61 \%$ demonstrated a $B R A F$ mutation. The presence of TC was significantly associated with TERT promoter and BRAF mutations. TERT predicted highly significant tumor relapse $(P<0.001)$. PTCs comprised of at least $10 \%$ TCs are associated with an adverse clinical outcome and should be reported accordingly. BRAF did not influence patient outcome. Nevertheless, a positive status should encourage the search for TCS. TERT promoter mutations are a strong predictor of tumor relapse, but their role as a surrogate marker for TCs is limited.
\end{abstract}

\author{
Key Words \\ - papillary thyroid carcinoma \\ - tall cell \\ - diagnostic criteria \\ - prognosis \\ - BRAF \\ - TERT
}

\section{Introduction}

Thyroid carcinoma is classified into five different morphological groups: papillary, follicular, medullary, poorly differentiated, and anaplastic/undifferentiated (DeLellis et al. 2004). These endocrine cancers account for $\sim 1 \%$ of all malignancies (Schlumberger 1998). Papillary thyroid carcinomas (PTCs) are among the most curable cancers, and total thyroidectomy followed by adjuvant radioiodine administration cures almost all PTC patients. Patient prognosis depends on age, sex, tumor size, and extrathyroidal extension, the latter two of which are reflected

Published by Bioscientifica Ltd 
in the UICC TNM staging system (Sobin et al. 2009). On a morphologic basis, PTCs are subdivided into different subtypes, as recognized by the WHO classification (DeLellis et al. 2004). Nevertheless, this subclassification has little clinical significance, because the different subtypes do not add independent prognostic value. As a result, the vast majority of PTCs are not routinely subclassified. A grading system for PTCs has been proposed that includes nuclear atypia, tumor necrosis, and vascular invasion as signs of a poorly differentiated PTC (Akslen \& LiVolsi 2000). However, most of these tumors would nowadays probably be classified as poorly differentiated thyroid carcinomas (Volante et al. 2007). Different staging systems for PTCs have been introduced. Unfortunately, they are very complex, and as a consequence, they are not used on a daily basis in most institutions. In fact, it is very difficult to predict which patients will suffer from recurrent disease or death from PTC and which will be cured by the combination of surgery and radioiodine treatment (Nikiforov et al. 2012).

Among the different PTC subtypes, the tall cell variant (TCV) is known to have a more aggressive clinical behavior (LiVolsi 2010). However, the morphological criteria for the diagnosis of this entity is not clearly defined by the WHO ('The TCV is composed predominantly of cells whose heights are at least three times their widths.'), and the percentage of tall cells (TCs) needed in a given tumor is defined variably in the literature (Ostrowski \& Merino 1996, DeLellis et al. 2004).

The oncogenic BRAF V600E mutation occurs in about $40-45 \%$ of PTCs (Nikiforov et al. 2012). It activates the MAPK signaling pathway in human cancer and has been shown to correlate with aggressive features in PTC, including extrathyroidal extension, lymph node metastasis, and the TCV (Kim et al. 2012, Koperek et al. 2012, Li et al. 2012, Xing et al. 2013). An increasing number of studies that include meta-analyses have been able to demonstrate an association between BRAF status and aggressive tumor behavior (Elisei et al. 2012, Kim et al . 2012, Li et al. 2012, Xing et al. 2013). Other studies, however, could not confirm this data, which has resulted in uncertainty about the value of BRAF in PTC (Ito et al. 2009, Cheng et al. 2011, Eloy et al. 2011, Koperek et al. 2012, Sancisi et al. 2012, Barbaro et al. 2014). One reason for this could be the fact that an adverse patient outcome with multiple tumor relapses and eventually death resulting from PTC is a rare event. As a matter of fact, only about $5 \%$ of PTCs will have an adverse outcome in consecutive clinicopathological series, and this has led to very small groups of high-risk tumors with limited statistical power in different studies (Handkiewicz-Junak et al. 2010).

Reactivation of the telomerase reverse transcriptase (TERT) gene, which encodes for the catalytic subunit of telomerase, is implicated in tumorigenesis and cell immortalization. The two promoter mutations C228T and C250T were recently reported in human melanomas and other human cancer types, including thyroid cancer (Huang et al. 2013, Liu et al. 2013a, Vinagre et al. 2013). They are novel mechanisms in tumor biology that generate de novo consensus-binding motifs for E-twenty-six transcription factors, increase the activity of the TERT promoter, and have potential clinical applications and prognostic value (Huang et al. 2013, Landa et al. 2013, Liu et al. 2013b).

The purpose of this study was to analyze the prevalence, histomorphology, and follow-up data of a cohort of PTC patients enriched for patients with a known adverse clinical outcome (ACO) based on a population of 1.3 million inhabitants over a 16-year period and to determine the threshold of TC within a given PTC that could impact patient outcome. Furthermore, we sequenced BRAF and TERT promoter mutations in all tumors and evaluated whether they can serve as surrogate markers for TCV and an ACO.

\section{Material and methods}

Because radioiodine treatment is the standard therapy for patients suffering from recurrent thyroid cancer, virtually all such patients are seen in the department of nuclear medicine. Three such departments (at the University Hospital Zürich, the City Hospital Triemli, and the Cantonal Hospital Winterthur) serve the 1.3 million inhabitants in the canton of Zürich (Statistics Do 2011). Fifty-seven patients were identified in these departments who had thyroid surgery between 1990 and 2006 and had an ACO. An ACO was defined as more than one tumor recurrence or tumor-related death. Sixty-eight age-, stageand sex-matched patients (without recurrence) treated for PTC at the University Hospital Zürich were used as the control group (CG; Table 1). Tumors with a size of $<1 \mathrm{~cm}$ were excluded from this study, because these microcarcinomas show a very indolent clinical course (Baloch \& LiVolsi 2006) and the significance of TC in this setting is beyond the scope of the study. This approach significantly enhanced the number of patients with an ACO. Twenty-one of the patients had lymph node metastases, whereas 104 patients were node negative.

Archival pathology specimens of the thyroid tumors were reevaluated according to the WHO classification by

Published by Bioscientifica Ltd. 
Table 1 Clinical and pathological characteristics between the adverse clinical outcome (ACO) group and the control group (CG); $\chi^{2}$ test

\begin{tabular}{|c|c|c|c|c|}
\hline & Total (n) & ACO & CG & $P$ value \\
\hline \multicolumn{5}{|l|}{ Age (years) } \\
\hline$<48$ & 69 (55.2\%) & $32(25.6 \%)$ & $37(29.6 \%)$ & 0.859 \\
\hline$\geq 48$ & $56(44.8 \%)$ & $25(20 \%)$ & $31(24.8 \%)$ & \\
\hline \multicolumn{5}{|l|}{ Sex } \\
\hline Male & $34(27.2 \%)$ & $20(16 \%)$ & $14(11.2 \%)$ & 0.106 \\
\hline Female & $91(72.8 \%)$ & $37(29.6 \%)$ & $54(43.8 \%)$ & \\
\hline \multicolumn{5}{|c|}{ (1) } \\
\hline pT 1-2 & $55(44 \%)$ & $18(14.4 \%)$ & 37 (29.6\%) & 0.012 \\
\hline pT 3-4 & $70(56 \%)$ & $39(31.2 \%)$ & $31(24.8 \%)$ & \\
\hline \multicolumn{5}{|c|}{ LN } \\
\hline No metastasis & $104(83.2 \%)$ & 38 (30.4\%) & $66(52.8 \%)$ & 0.001 \\
\hline Metastasis & $21(16.8 \%)$ & $19(15.2 \%)$ & $2(1.6 \%)$ & \\
\hline \multicolumn{5}{|l|}{ TC $(\%)$} \\
\hline $\mathrm{TC}<10$ & 77 (61.6\%) & $21(16.8 \%)$ & $56(44.8 \%)$ & 0.00001 \\
\hline $\mathrm{TC} \geq 10$ & $48(38.4 \%)$ & $36(28.8 \%)$ & $12(9.6 \%)$ & \\
\hline \multicolumn{5}{|l|}{$B R A F$ total $^{a}$} \\
\hline WT & $49(39.2 \%)$ & $17(13.6 \%)$ & $32(25.6 \%)$ & 0.066 \\
\hline Mutated & $76(60.8 \%)$ & $40(32.0 \%)$ & $36(28.8 \%)$ & \\
\hline \multicolumn{5}{|c|}{ 年 } \\
\hline WT & $102(92.7 \%)$ & 45 (40.9\%) & $57(51.8 \%)$ & 0.002 \\
\hline Mutated & $8(7.3 \%)$ & $8(7.3 \%)$ & $0(0 \%)$ & \\
\hline
\end{tabular}

${ }^{a}$ Result of $B R A F$ testing by pyrosequencing or by the VE1 antibody when no $B R A F$ mutational testing by pyrosequencing was possible.

three pathologists who were blinded to the clinicopathological data (M D, A S, and A P), and a consensus diagnosis was rendered (DeLellis et al. 2004). The tumor stage was reclassified based on the seventh TNM classification (Sobin et al. 2009). TCs were defined as cells that were more than three times as high as they were wide, often with an eosinophilic cytoplasm (Nikiforov et al. 2012). A few examples and pitfalls are shown in Fig. 1. Although the so-called 'tram-track' pattern, especially at low power, is a very helpful feature, not all areas showing this growth pattern are TCs. Furthermore, areas that exhibit a classic PTC growth pattern can be comprised of true TCs, which thus makes it mandatory for the pathologist to examine all tumors at high magnification. Nuclear stratification, intranuclear inclusions, and characteristic coffee bean infoldings of the nuclear membrane were frequently seen (Nikiforov et al. 2012).

The percentage of TCs was recorded semiquantitatively in each tumor in $10 \%$ increment steps, ranging from 0 to $100 \%$; the lowest recorded amount of TC in a given tumor was therefore $10 \%$. All available slides were assessed in each tumor $(6.1 \pm 4.5$ slides per case in the $C G$ and $5.0 \pm 4.5$ slides in the ACO group). Tumors that had anaplastic or poorly differentiated areas, as defined by the Turin criteria, were excluded from the study (Volante et al. 2007) and have been reported elsewhere (Dettmer et al. 2011, 2012).

DNA was extracted using the DNeasy Blood and Tissue kit, and all of the samples underwent BRAF pyrosequencing mutation analysis on the PyroMark Q24 System (Qiagen, Hombrechtikon, Switzerland) according to the manufacturer's instructions. The primers had the following sequence: forward: 5'-TGAAGACCTCACAGTAAAAATAGG-3'; reverse: 5'-TCCAGACAACTGTTCAAACTGAT-3'; sequencing primer: 5'-TGATTTTGGTCTAG-CTACA-3'. An allelic fraction of $\geq 10 \%$ mutant alleles was defined as positive for the mutation.

A tissue microarray (TMA) was constructed and stained with the BRAF V600E mutation-specific antibody as previously described (Koperek et al. 2012, Boos et al. 2013). A tumor was considered positive when a distinct, homogenous immunoreaction was seen in the cytoplasm of all of the cancer cells. Immunohistochemistry (IHC) and molecular analysis were performed on the same tissue block.

TERT promoter mutations were assessed by PCR, followed by Sanger Sequencing as described previously (Liu et al. 2013a).

The sample distribution was analyzed using the Kolmogorov-Smirnov test. $\chi^{2}$, Kendall's tau_b, KruskalWallis, Kaplan-Meier and COX regression tests were performed using SPSS version 21.0 (SPSS, Inc., IBM, Chicago, IL, USA). A $P$ value of $<0.05$ was considered statistically significant. The study was approved by the Cantonal Research Ethics Board, Zürich (STV 28-2006).

\section{Results}

Fifty-seven PTC patients with ACO and 68 PTC patients in the CG were analyzed. The characteristics of the study population are summarized in Tables 1 and 2. The means \pm s.D. for the different follow-up times in months were: overall survival (OS): $81.97 \pm 48.42$; tumor-specific survival (TSS): $81.97 \pm 48.42$; relapse-free survival (RFS): 51.78 \pm 50.97 ; CG: $81.88 \pm 48.5$; and ACO: $81.5 \pm 49.5$. There were 68 classic PTCs, 47 follicular variants of PTC (FVPTC), and ten PTCs of special subtypes (three diffuse sclerosing, two columnar cell, two solid, two warthin-like, and one oncocytic variant). Seventy-seven PTCs did not display any detectable TCs, 27 PTCs showed $>10 \%$ but $<50 \%$ TCs, and 21 tumors had $\geq 50 \%$ TCs. The distribution of TCs and the important clinical endpoints OS, TSS, and RFS are summarized in Table 2 and Supplementary Table 1 , see section on supplementary data given at the end of this article.

Published by Bioscientifica Ltd. 

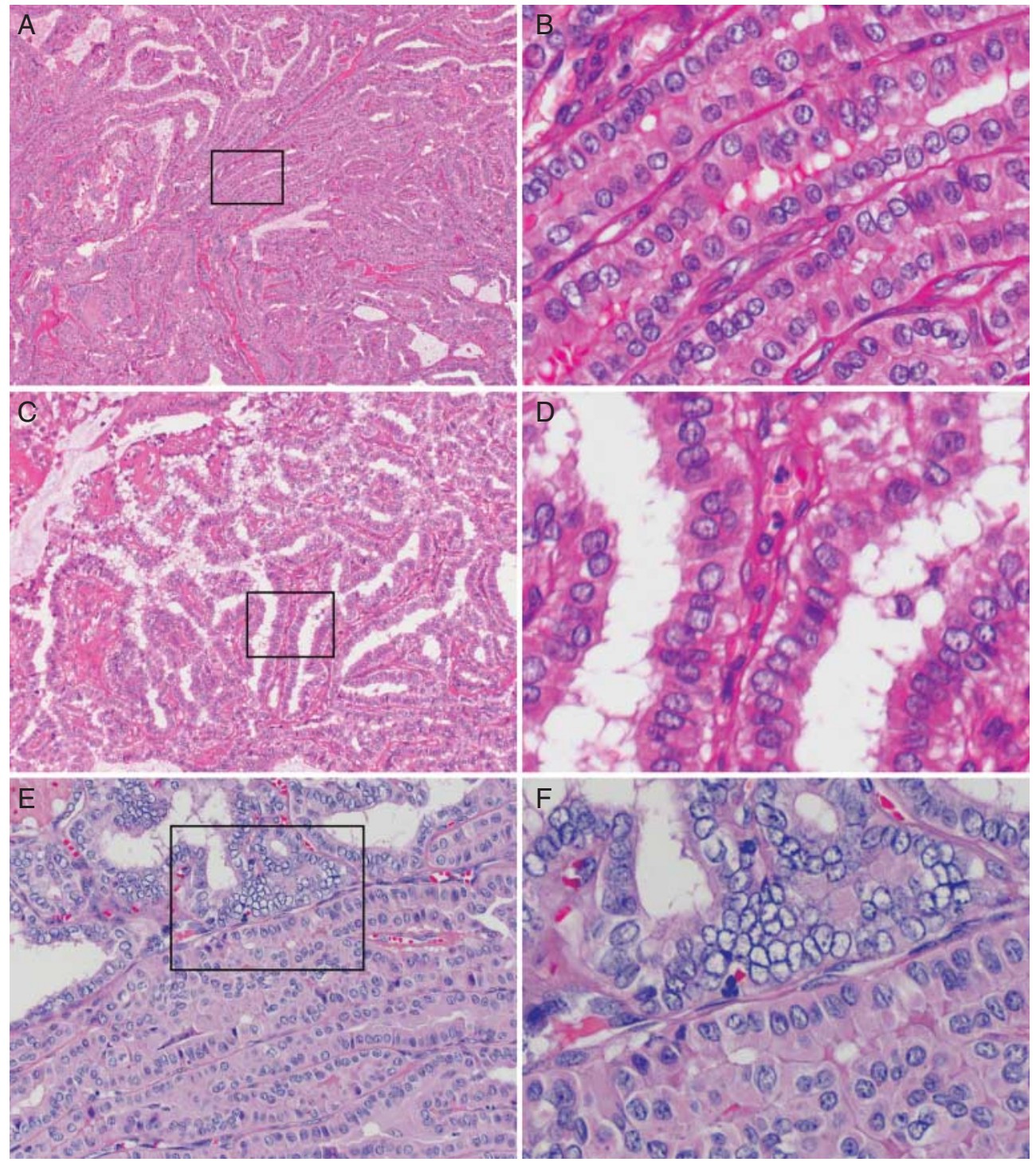

\section{Figure 1}

(A) Papillary cancer, tall cell variant: tumor cells are at least three times as high as they are wide and show an eosinophilic cytoplasm and elongated follicles (HE, 200X). (B) Same tumor as (A). Papillary cancer, tall cell variant: cells arranged in a 'tram-track' pattern with eosinophilic cytoplasm (HE, $400 \times$ ). (C) Papillary cancer, tall cell variant: papillary growth pattern with delicate branching of papillae (HE, 200X). (D) Same tumor as (C). Papillary cancer, tall cell variant: cells growing in a classic papillary fashion

The tumors comprising of $10-50 \%$ TCs showed a presence of TCs predominantly at the invasive front, whereas tumors harboring $\geq 50 \%$ TC showed a presence of TCs in the center of the tumor as well.

\section{Tall cells}

The presence of TCs showed significant correlation with patient survival, relapse, and tumor stage.
$(\mathrm{HE}, 400 \times)$. (E) Not all cells in these tumors are at least three times high as they are wide. However, tumor cells growing in the 'tram-track' pattern should trigger a careful search for tall cells (HE, 200×). (F) Same tumor as (E). Tumor cells are cut tangential to their base (upper). Cells can only be assessed where the basal membrane is seen (lower). These tumor cells are classic tall cells, often with nuclear grooves and elongated follicles $(\mathrm{HE}, 400 \times)$.

Clinicopathological data for the tumors were also correlated with the different thresholds for TC presence in the tumors, and ROC curves were calculated to assess the best cutoff (Supplementary Fig. 1 and Table 2, see section on supplementary data given at the end of this article). TCs of $>10 \%$ correlated with lymph node metastasis $(P<0.001)$ but not with organ metastases $(P<0.223)$. TCs of $\geq 50 \%$ did not correlate with lymph node metastasis $(P<0.141)$ nor with organ metastasis $(P<0.601)$. 
Table 2 Clinicopathological characteristics of the study population for papillary thyroid carcinoma (PTC) with different cutoffs for the tall cell variant (TCV) of PTC; $\chi^{2}$ test

\begin{tabular}{|c|c|c|c|c|c|c|c|}
\hline & Total $(n)$ & TC $<10 \%(n)$ & TC $\geq 10 \%(n)$ & $P$ value & TC $<50 \%(n)$ & TC $\geq \mathbf{5 0} \%$ (n) & $P$ value \\
\hline \multicolumn{8}{|l|}{ Age (years) } \\
\hline$<48$ & $69(55.2 \%)$ & $44(35.2 \%)$ & $25(20 \%)$ & 0.586 & $62(49.6 \%)$ & $7(5.6 \%)$ & 0.032 \\
\hline$\geq 48$ & $56(44.8 \%)$ & $33(26.4 \%)$ & $23(18.4 \%)$ & & $42(33.6 \%)$ & $14(11.2 \%)$ & \\
\hline \multicolumn{8}{|l|}{ Sex } \\
\hline Male & $34(27.2 \%)$ & $17(13.6 \%)$ & $17(13.6 \%)$ & 0.147 & $26(20.8 \%)$ & $8(6.4 \%)$ & 0.282 \\
\hline Female & $91(72.8 \%)$ & $60(48 \%)$ & $31(24.8 \%)$ & & $78(62.4 \%)$ & $13(10.4 \%)$ & \\
\hline \multicolumn{8}{|l|}{ pT } \\
\hline pT 1-2 & $55(44 \%)$ & $40(32 \%)$ & $15(12 \%)$ & 0.027 & $51(40.8 \%)$ & $4(3.2 \%)$ & 0.015 \\
\hline pT 3-4 & $70(56 \%)$ & $37(29.6 \%)$ & $33(26.4 \%)$ & & $53(42.4 \%)$ & $17(13.6 \%)$ & \\
\hline \multicolumn{8}{|l|}{ LN } \\
\hline No metastasis & $104(83.2 \%)$ & $74(59.2 \%)$ & $30(24 \%)$ & 0.0001 & $90(72 \%)$ & $14(11.2 \%)$ & 0.049 \\
\hline Metastasis & $21(16.8 \%)$ & $3(2.4 \%)$ & $18(14.4 \%)$ & & $14(11.2 \%)$ & $7(5.6 \%)$ & \\
\hline \multicolumn{8}{|l|}{ OS } \\
\hline $\begin{array}{l}\text { Censored } \\
\text { OS }\end{array}$ & $111(88.8 \%)$ & $75(60 \%)$ & $36(28.8 \%)$ & 0.0001 & $97(77.6 \%)$ & $14(11.2 \%)$ & 0.002 \\
\hline Death & $14(11.2 \%)$ & $2(1.6 \%)$ & $12(9.6 \%)$ & & $7(5.6 \%)$ & $7(5.6 \%)$ & \\
\hline \multicolumn{8}{|l|}{ TSS } \\
\hline $\begin{array}{l}\text { Censored } \\
\text { TSS }\end{array}$ & $118(94.4 \%)$ & $77(61.6 \%)$ & $41(32.8 \%)$ & 0.001 & $102(81.6 \%)$ & $16(12.8 \%)$ & 0.001 \\
\hline Death & $7(5.6 \%)$ & $0(0 \%)$ & $7(5.6 \%)$ & & $2(1.6 \%)$ & $5(4 \%)$ & \\
\hline \multicolumn{8}{|l|}{ RFS } \\
\hline $\begin{array}{l}\text { Censored } \\
\text { RFS }\end{array}$ & $68(54.4 \%)$ & $56(44.8 \%)$ & $12(9.6 \%)$ & 0.0001 & $66(52.8 \%)$ & $2(1.6 \%)$ & 0.0001 \\
\hline Relapse & $57(45.6 \%)$ & $21(16.8 \%)$ & $36(28.8 \%)$ & & $38(30.4 \%)$ & $19(15.2 \%)$ & \\
\hline
\end{tabular}

TC, tall cells; OS, overall survival; TSS, tumor specific survival; RFS, relapse free survival.

Kaplan-Meier survival analysis showed significant reduction in OS, TSS, and RFS for tumors that had more than $10 \%$ TCs (each: log-rank $P<0.001$ ). To further determine what proportion of $\geq 10 \%$ TCs impacts patient prognosis, we subcategorized this group into two groups, namely, $10-50$ and $\geq 50 \%$ TC area. There were no significant differences between the two groups with regards to OS, TSS, or RFS, but in the group with 10-50\% TCs, there was a tendency for less aggressive behavior as compared to the group with $\geq 50 \%$ TC area (Fig. 2).

Multivariate Cox regression analysis was performed using patient age, sex, tumor stage, and TC tumor area ( $<10 \%$ vs $\geq 10 \%$ ) for OS, RFS, and TSS. For RFS, TC $\geq 10 \%$ was the only parameter that was significant $(P<0.0001$,
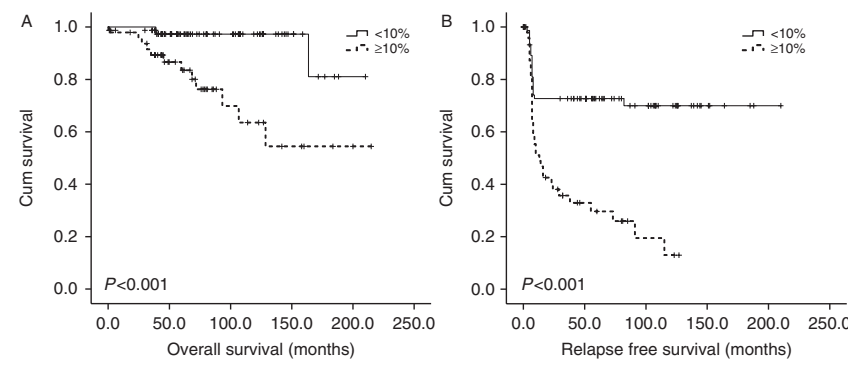

Figure 2

(A) Kaplan-Meier, overall survival (OS); tall cells $<10$ and $\geq 10 \%$; log-rank $P<0.001$. TC $<10 \%$ : mean \pm s.E.M. $200.07 \pm 7.37 ; 95 \% \mathrm{Cl} 185.62,214.52$; TC $\geq 10 \%$ : mean \pm s.E.M. $152.14 \pm 14.90 ; 95 \%$ Cl 122.93, 181.34. (B) KaplanMeier, relapse-free survival; tall cells $<10$ and $\geq 10 \%$; log-rank $P<0.001$. TC $<10 \%$ : mean \pm s.E.M. $150.98 \pm 10.9 ; 95 \%$ Cl 129.63, 172.32. TC $\geq 10 \%$ : mean \pm s.E.M. $40.20 \pm 7.0 ; 95 \%$ Cl 26.49, 53.91. (C) Kaplan-Meier, OS; tall cells $<10 \%$ vs $\geq 10-<50 \%$, log-rank $P<0.001$ and tall cells $\geq 10-<50 \%$ vs $\geq 50 \%$; log-rank $P<0.518$. TC $<10 \%$ : mean \pm s.E.M. $200.07 \pm 7.37 ; 95 \% \mathrm{Cl}$
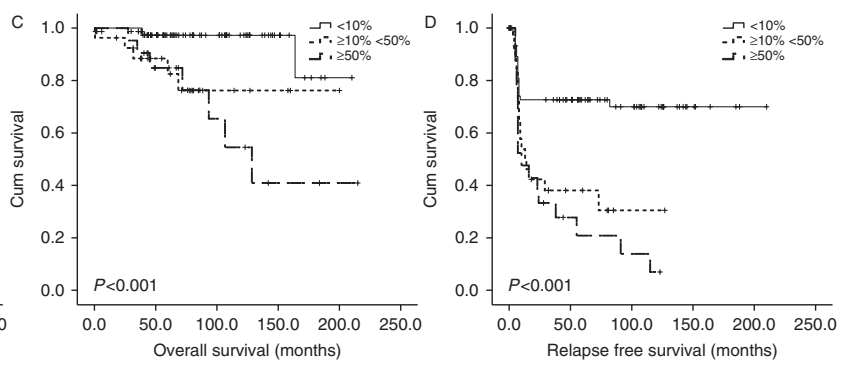

185.62, 214.52. TC $\geq 10-<50 \%$ : mean \pm s.E.M. $162.48 \pm 14.94 ; 95 \%$ Cl 133.20 , 191.76. TC $\geq 50 \%$ : mean \pm s.E.M. $138.85 \pm 20.18 ; 95 \%$ Cl $99.30,178.40$. (D) Kaplan-Meier, relapse-free survival; tall cells $<10 \%$ vs $\geq 10-<50 \%$, log-rank $P<0.001$; and tall cells $\geq 10-<50 \%$ vs $\geq 50 \%$; log-rank $P<0.379$. TC $<10 \%$ : mean \pm s.E.M. $150.98 \pm 10.9 ; 95 \%$ Cl 129.63, 172.32 . TC $\geq 10-<50 \%$ : mean \pm s.E.M. $50.32 \pm 10.87 ; 95 \%$ Cl 29.01, 71.63 . TC $\geq 50 \%$ : mean \pm s.E.M. $32.43 \pm 8.58 ; 95 \%$ Cl 15.62, 49.24

Published by Bioscientifica Ltd. 
$\operatorname{Exp}(B)=3.6)$. For $O S$, the factors that were significant were age $(P<0.010, \operatorname{Exp}(\mathrm{B})=6.3)$, and TC $\geq 10 \%(P<0.001$, $\operatorname{Exp}(\mathrm{B})=12.9)$. The analysis could not be performed for TSS, because no patient in the TC $<10 \%$ group died. However, when the analysis for TSS was performed using the threshold of TC $\geq 50 \%$, it was significant $(P<0.008$, $\operatorname{Exp}(B)=9.3)$. The Kruskal-Wallis test revealed a significant association between the number of relapses and the percentage of TCs found in a given tumor $(P<0.001$; Supplementary Table 3 , see section on supplementary data given at the end of this article).

\section{BRAF}

Pyrosequencing analysis detected BRAF V600E in 72 PTC cases (61\%), whereas 46 tumors (39\%) were negative. All of the mutations were V600E; other BRAF mutations were not detected. The sensitivity was higher as compared to the mutation-specific antibody, which detected the mutation in 63 cases $(50.4 \%)$ and which was negative in the other 62 patients (49.6\%). The allelic fraction of BRAF (29.4 \pm 13.5 , range 10-46) mutation did not correlate with patient outcome. Pyrosequencing was more sensitive in nine discrepant cases, and it detected the BRAF mutation when the antibody was negative. Two of these cases had subsequent lymph node metastases, which were then positive for $B R A F$ by the antibody. Only two tumors that showed a positive IHC for V600E were negative by pyrosequencing. In summary, there was an excellent, highly significant correlation between both detection methods ( $P<0.001, r=0.600$; Supplementary Table 2$)$.

$B R A F$ status was not associated with patient outcome in the Kaplan-Meier analysis or the Cox regression multivariate analysis (Fig. 3). There were no associations of $B R A F$ mutations with lymph node or organ metastases.
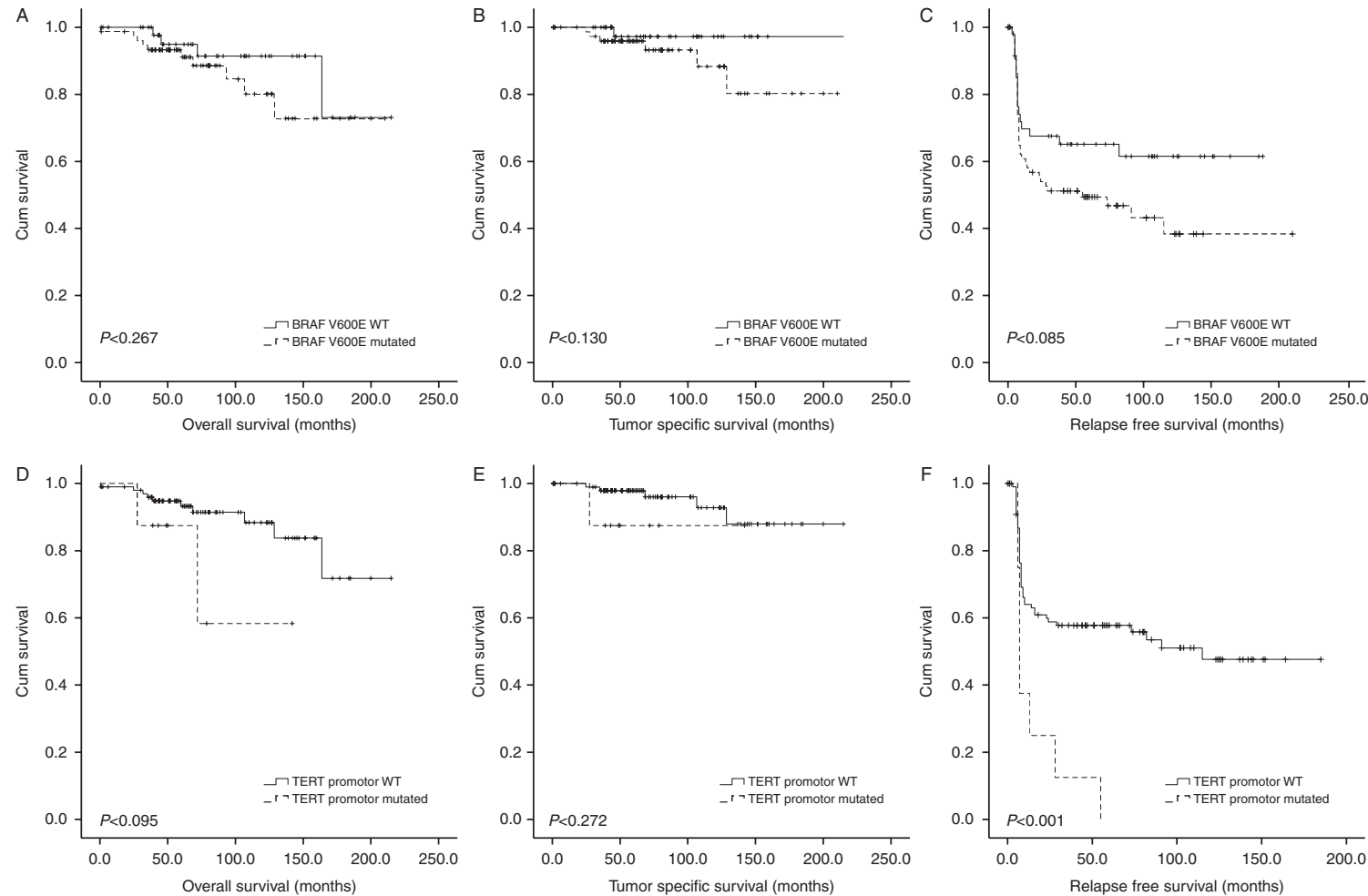

\section{Figure 3}

The influence of $B R A F(A, B$ and $C$ ) and TERT promoter mutations (D, E and $F$ ) on overall survival, tumor-specific survival (TSS), or relapse-free survival in patients with PTC; all log-rank test. (A) Kaplan-Meier, overall survival; BRAF wt: mean \pm S.E.M. 191.75 $\pm 11.04 ; 95 \%$ Cl 170.11, 213.38; BRAF V600E: mean \pm s.E.M. $175.60 \pm 10.30 ; 95 \% \mathrm{Cl} 155.40$, 195.79. (B) Kaplan-Meier, TSS; BRAF wt: mean \pm s.E.M. 210.22 $44.65 ; 95 \%$ Cl 201.10, 219.33; BRAF V600E: mean \pm s.E.M. 187.34 $\pm 9.30 ; 95 \%$ Cl 169.11, 205.58. (C) Kaplan-Meier, relapse-free survival; $B R A F$ wt: mean \pm s.E.M. $121.822 \pm 12.76 ; 95 \% \mathrm{Cl} 96.82$, 146.82; BRAFV600E: mean \pm s.E.M. $96.99 \pm 12.08 ; 95 \%$ Cl 73.31, 120.67 .
(D) Kaplan-Meier, overall survival; TERT promoter wt: mean \pm s.E.M. 196.64 $\pm 8.84 ; 95 \%$ Cl 169.31, 203.96; TERT promoter mutated: mean \pm s.E.M. 107.18 $\pm 19.80 ; 95 \% \mathrm{Cl} 68.37,145.99$. (E) Kaplan-Meier, TSS; TERT promoter wt: mean \pm s.E.M. $200.60 \pm 6.39 ; 95 \%$ Cl 188.08, 213.11; TERT promoter mutated: mean \pm s.E.M. $127.63 \pm 13.38 ; 95 \%$ Cl 101.40, 153.86. (F) KaplanMeier, relapse-free survival; TERT promoter wt: mean \pm s.E.M. $101.34 \pm 9.09$; 95\% Cl 83.52, 119.16; TERT promoter mutated: mean \pm s.E.M. $16.13 \pm 6.15$; $95 \% \mathrm{Cl} 4.07,28.18$. 
Table 3 Tall cells, BRAF, and TERT promoter mutation status of the study population for papillary thyroid carcinoma (PTC) with different cutoffs for the TCV; $\chi^{2}$ test. BRAF pyro, BRAF V600E mutational status as detected by pyrosequencing; BRAF antibody, BRAF V600E mutational status as detected by the mutation-specific VE1 antibody for BRAF V600E; BRAF total, BRAF V600E mutational status as detected by pyrosequencing when available and otherwise by the mutation-specific VE1 antibody for $B R A F$ V600E

\begin{tabular}{l} 
\\
\hline BRAF pyro \\
WT \\
Mutated \\
BRAF antibody \\
WT \\
Mutated \\
BRAF total \\
WT \\
Mutated \\
TERT \\
WT \\
Mutated
\end{tabular}

\begin{tabular}{c}
\hline Total $(\boldsymbol{n})$ \\
\hline $46(39 \%)$ \\
$72(61 \%)$ \\
$62(49.6 \%)$ \\
$63(50.4 \%)$ \\
$49(39.2 \%)$ \\
$76(60.8 \%)$ \\
$102(92.7 \%)$ \\
$8(7.3 \%)$
\end{tabular}

\begin{tabular}{c}
\hline TC $<\mathbf{1 0 \%}(\boldsymbol{n})$ \\
\hline $37(31.4 \%)$ \\
$35(29.7 \%)$ \\
$45(36 \%)$ \\
$32(25.6 \%)$ \\
$39(31.2 \%)$ \\
$38(30.4 \%)$ \\
$65(59.1 \%)$ \\
$1(0.9 \%)$ \\
\hline
\end{tabular}

\begin{tabular}{c}
\hline TC $\geq \mathbf{1 0 \%}(\boldsymbol{n})$ \\
\hline $9(7.6 \%)$ \\
$37(31.4 \%)$ \\
$17(13.6 \%)$ \\
$31(24.8 \%)$ \\
$10(8 \%)$ \\
$38(30.4 \%)$ \\
$37(33.6 \%)$ \\
$7(6.4 \%)$ \\
\hline
\end{tabular}

\begin{tabular}{c}
\hline P value \\
\hline 0.001 \\
0.017 \\
0.001 \\
0.004 \\
\hline
\end{tabular}

\begin{tabular}{c}
\hline TC $<\mathbf{5 0 \%}(\boldsymbol{n})$ \\
\hline $41(34.7 \%)$ \\
$56(47.5 \%)$ \\
$53(42.4 \%)$ \\
$51(40.8 \%)$ \\
$44(35.2 \%)$ \\
$60(48 \%)$ \\
$89(80.9 \%)$ \\
$2(1.8 \%)$ \\
\hline
\end{tabular}

\begin{tabular}{c}
\hline TC $\geq \mathbf{5 0 \%}(\boldsymbol{n})$ \\
\hline $5(4.2 \%)$ \\
$16(13.6 \%)$ \\
$9(7.2 \%)$ \\
$12(9.6 \%)$ \\
$5(4 \%)$ \\
$16(12.8 \%)$ \\
$13(11.8 \%)$ \\
$6(5.5 \%)$ \\
\hline
\end{tabular}

\begin{tabular}{l}
\hline P value \\
0.143 \\
0.633 \\
0.088 \\
0.0003 \\
\hline
\end{tabular}

\section{TCs and BRAF}

Sixteen out of 21 patients (76\%) had the $B R A F$ mutation when the 50\% cutoff for the TCV was applied. This went up to $79 \%$ (38 out of 48 patients) when the $10 \%$ cutoff for the TCV diagnosis was applied. The amount of TC within a given tumor was significantly associated with $B R A F$ status $(P<0.002$; Table 3, Supplementary Table 1$)$.

The allelic fraction as determined by pyrosequencing was influenced by the amount of TC within a tumor $(P<0.034, r=0.156$; Kendall's tau_b). There was no significant association between $B R A F$ status and an ACO on univariate or multivariate analysis for either the $10 \%$ or for the $50 \%$ cutoff when we analyzed only the TC tumors (Table 1, Supplementary Tables 2 and 3).

\section{TCs, BRAF, and TERT}

TERT promoter mutations were detected in eight tumors (7.3\%). The C250T mutation was found in three tumors, and the C228T mutation was found in five. Six patients with TERT promoter mutations were also BRAF mutated, whereas two were not $(P<0.49)$. TC morphology correlated significantly with this mutation $(P<0.0001$, $r=0.308$ ); six of these tumors had TC morphology in $\geq 50 \%$, whereas one had $30 \%$ TC and one had none. All eight patients with the TERT promoter mutation had a tumor relapse $(P<0.001)$. Tumors that were TERT promoter mutated and $B R A F$ mutated behaved significantly worse than $B R A F$ mutated tumors alone did (log-rank $P<0.019$; Table 1 and Supplementary Table 2).

TERT promoter mutations, together with pT stage, remained an independent predictor of tumor relapse in

a multivariate analysis (TERT promoter mutation: $P<0.005, \operatorname{Exp}(\mathrm{b})=3.18$; $\mathrm{pT}$ stage: $P<0.019, \operatorname{Exp}(\mathrm{b})=$ 1.58). However, when TCs were included in the analysis, they remained the single independent predictor of RFS $(P<0.0001, \operatorname{Exp}(b)=3.04)$, whereas the other two factors dropped out (Supplementary Table 3).

The numbers of some parameters do not add up to the total number of patients included in the study because of dropouts in DNA quality and the consecutive failure of mutational testing or because of dropout of cases on the TMA.

\section{Discussion}

In this study, we analyzed a large cohort of PTC and TCV with an ACO, delineated the proportion of TC that is needed to determine patient outcome, and assessed the role of $B R A F$ and TERT promoter mutations in this setting. In the study, a $10 \%$ cutoff of TC defines a detrimental prognosis. BRAF mutation status does not correlate with adverse outcome, but it is more frequent in TCV than it is in classical PTC. TERT mutations are rare, but they are associated with a very aggressive course.

Previous clinicopathological studies on TCV PTC analyzed small groups of tumors with ACO, which thereby limited their statistical power (Ostrowski \& Merino 1996, LiVolsi 2010). In this study, the number of patients with ACO was increased to a relatively large sample size via the identification of patients in nuclear medicine departments. This approach increased the statistical power in determining a cutoff of TC leading to poor prognosis. This patient selection is, on the other hand, also a limitation of the study, because it does not reflect the normal patient

Published by Bioscientifica Ltd 
population. We can therefore not exclude the possibilities that we overestimated the effect of TC in tumors with an ACO and that TCs are much more frequently encountered in a consecutive series of patients when they do not account for an ACO. However, in our age-, stage- and sexmatched cohort, this was not the case.

The TCV PTC is a distinct entity of thyroid tumors that is associated with an unfavorable patient outcome. The threshold of proportion of TCs in a given carcinoma to allow for the diagnosis of TCV is poorly defined and differs in the literature from no information at all to $10-75 \%$ (Sobrinho-Simoes et al. 1989, Ostrowski \& Merino 1996, Akslen \& LiVolsi 2000, DeLellis et al. 2004, LiVolsi 2010). Our results confirm that PTCs comprising more than 50\% TCs have an ACO. Although this result was expected, it settles the finding in a robust study population. Survival analysis showed that there was a clear difference between TC and non-TC PTCs using this 50\% cutoff. However, the results were more interesting when a cutoff at $10 \%$ was introduced, because the influence of a minor TC component is unclear and controversial (LiVolsi 2010, Nikiforov et al. 2012). To exclude the possibility that the group of PTCs comprising of $\geq 50 \%$ TCs skewed the analysis and that a TC component of $10-50 \%$ did not severely affect patient outcome, we separated the tumors into three groups, $<10 \%$ TCs, $10-50 \%$ TC, and $\geq 50 \%$ TC. Kaplan-Meier analysis revealed that the presence of at least $10 \%$ TCs in a PTC significantly impacted the patient outcome for OS, TSS, and RFS. Moreover, a PTC with $\geq 10 \%$ TCs is the only significant factor in a multivariate analysis, which included age, sex, and tumor stage, for ACO.

It has already been proposed by Sobrinho and others (Sobrinho-Simoes et al. 1989, LiVolsi 2010) that it is important for pathologists to report the number of TCs seen in a given tumor, few as they may be. Two studies have suggested that a minor TC component may determine patient outcome, but they were not able to confirm this in a univariate or multivariate analysis respectively (Beninato et al. 2013, Ganly et al. 2013). The first study (Beninato et al. 2013) conducted a review on cases that had been diagnosed as TCV or PTC with a minor TC component. With such an approach, we would have missed most of the TCVs in this study. In fact, only three PTCs consisting exclusively of TCs were diagnosed as TCVs in the original pathology report. All of the remaining PTCs were originally diagnosed as either classical PTCs or FVPTCs, even when a threshold of 50\% was applied. These underdiagnoses could be a result of the rarity of this condition and a lack of awareness on the part of the surgical pathologists, on the one hand, or a result of the ambiguous definition of the condition, on the other hand. The second study (Ganly et al. 2013) defined TCs as cells with a height that is twice the size of their width and therefore included as TCVs tumors that would not be included as TCVs in this work. Our results indicate that the strict application of the 2004 WHO definition of TCs as cells with a length that is thrice their width better stratifies patients (DeLellis et al. 2004). That study also had only a few patients with adverse events. Because of these reasons, it was probably therefore not significant in the multivariate analysis.

In this study, it is evident that the presence of a TC component of $10-50 \%$ significantly and independently affects patient prognosis and that there is no statistical difference between the group with a $10-50 \%$ TC component and that with a $\geq 50 \%$ TC component. The PTCs with $10-50 \%$ TCs would be regarded as conventional PTCs or as PTCs with TC features by most authors (Ghossein \& Livolsi 2008, LiVolsi 2010). At this point, it is important to specify that we examined approximately six tumor blocks per patient and that examining only one block per tumor would have lowered the rate of detection of TCV by $11 \%$ when using the $10 \%$ cutoff. To our knowledge, no image analysis tool is available that would be able to identify TCs within a PTC and to quantify their amount in a given tumor.

The Kaplan-Meier survival analysis in this study suggests that there might be a difference between the tumors that harbor a $10-50 \%$ TC component vs a $\geq 50 \%$ TC component, with the former showing a tendency for less aggressive behavior. We propose two potential explanations for this finding. First, there could be a limitation in the morphological detection of TC areas in the sub 10\% range that could lead to these tumors being categorized in the 10-50\% TC group, which would thereby account for the intermediate results in the Kaplan-Meier analysis. This also implies that the greater the TC component that was identified, the higher the possibility that the tumor was truly a TCV of PTC. The second explanation for this finding is that there could be a gradual increase of TC that leads to a gradually increased aggressiveness. Further support for the second explanation can be found the comparison of TCV to other solid carcinomas. Different subclones in tumors play an important role in the formation of tumor progression and metastasis (Yachida et al. 2010). These more aggressive subclones could gradually replace the less aggressive clones. A potential driver mutation for TCV PTC might be the BRAF V600E mutation. Indeed, this work confirms

Published by Bioscientifica Ltd. 
the fact that $B R A F$ mutations are more frequently observed in TCVs as compared to PTCs (Nikiforova et al. 2003). Furthermore, it demonstrates that PTCs with $B R A F$ mutations have a higher frequency of extrathyroidal extension and nodal metastases than do those that are negative for this mutation (Nikiforova et al. 2003).

Although this study was not designed to analyze genetic intratumoral heterogeneity, we observed 11 of 125 tumors with different $B R A F$ mutation results in two regions, and the immunohistochemical BRAF V600E detection was heterogeneous in two cases, whereas the allelic fraction by pyrosequencing was more than $30 \%$ in both cases. These findings support the fact that $B R A F$ tumor heterogeneity occurs in PTC (Guerra et al. 2012a), but its prognostic role is unclear, because the allelic fraction did not correlate with patient outcome, which is in contrast to previous findings (Guerra et al. 2012b). In fact, we did not detect any significant association between the BRAF status of the tumors and patient outcome, either when analyzing all of the tumors or when analyzing only the TCV tumors. These findings are supported by other groups that were also not able to find such a relationship (Ito et al. 2009, Eloy et al. 2011, Koperek et al. 2012, Sancisi et al. 2012, Barbaro et al. 2014). Epidemiologically, it is not surprising that the $B R A F$ mutation does not predict $A C O$, given that $B R A F$ mutations can be found in about $40-50 \%$ of PTCs, whereas $<5 \%$ of these tumors have an aggressive clinical course. Therefore, we believe that additional factors have to be present that account for the ACO in patients that harbor this mutation.

One of these potential additional factors could be TERT promoter mutations. They were recently discovered to be a novel mechanism of telomerase activation, which is known to be centrally involved in the tumorigenesis of various human cancer types, including thyroid cancer (Vinagre et al. 2013). From a diagnostic standpoint, it is worthwhile to mention that TERT promoter mutations were not detected in medullary thyroid carcinomas nor in benign lesions or normal thyroids (Vinagre et al. 2013). More importantly, recent studies that included TCGA data have reported that TERT promoter mutations play a role in aggressive thyroid cancers and in tumor progression from well-differentiated to poorly differentiated and anaplastic thyroid carcinomas. The various studies found a frequency in PTC that ranged from 8 to $25 \%$ and was associated with an unfavorable prognosis (Liu et al. 2013a,b, Vinagre et al. 2013, Cancer Genome Atlas Research 2014, Melo et al. 2014, Shimamura et al. 2014). They occur significantly more often in TCVs (30\%) as compared to conventional PTCs or FVPTCs (10\%) and in poorly differentiated thyroid carcinomas (21-37\%) as compared to the differentiated subtypes (PTC or FTC: 12\%), and they have a high incidence in anaplastic thyroid carcinomas (13-46\%) (Liu et al. 2013b, Vinagre et al. 2013). Although TERT promoter mutations significantly contribute to an ACO in PTC patients, many TCV PTCs with an ACO were TERT WT. Thus, other molecular players that are responsible for TC morphology and an ACO have yet to be discovered.

\section{Conclusion}

We showed that the presence of as few as $10 \%$ TCs within a PTC significantly affects patient prognosis. Therefore, these tumors should be classified accordingly and reported by pathologists, so that treating clinicians are aware that they are dealing with aggressive neoplasms. BRAF mutation did not affect patient outcome. Nevertheless, a mutation analysis for $B R A F$ might be helpful in clinical management, because a positive $B R A F$ status may trigger the search for TCs in order to predict patient outcome, and new therapeutics that inhibit the mutated protein are now clinically available. TERT promoter mutations are too rare to serve as a surrogate marker for TCs. However, they are a novel tool for predicting molecularly an adverse outcome in a subset of patients, and their implementation in daily molecular diagnostics is worthwhile.

\section{Supplementary data}

This is linked to the online version of the paper at http://dx.doi.org/10.1530/ ERC-15-0057.

\section{Declaration of interest}

D Capper declares shared inventorship of the VE1 antibody and has applied for a patent for the diagnostic use of VE1. Under a licensing agreement between Ventana Medical Systems, Inc., Tucson, AZ, and the German Cancer Research Center, D Capper is entitled to a share of the royalties received by the German Cancer Research Center on the sales of VE1 antibody. The terms of this arrangement are being managed by the German Cancer Research Center in accordance with its conflict of interest policies.

\section{Funding}

M S Dettmer was supported by the Fondation pour la recherche NuovoSoldati, the Research Support Foundation, and the Gertrud Hagmann Stiftung für Malignomforschung.

\section{Acknowledgements}

We thank Dr Haldemann and Dr Meili for providing us with clinicopathological data from their nuclear medicine departments. We also thank Dr Flury, Cantonal hospital Winterthur, Dr Moll, Cantonal hospital Münsterlingen, Prof. Diebold, Cantonal hospital Luzern, Prof. von

Published by Bioscientifica Ltd. 
Hochstetter, Institut Enge, Dr Scheidegger, Viollier Basel, Dr Baltisser, Institut Regenbogen, and Dr Riehle, Institut Arnaboldi, for providing tissue samples and for their helpful collaboration. We thank Prof. Dr I Zlobec for reviewing the manuscript.

\section{References}

Akslen LA \& LiVolsi VA 2000 Prognostic significance of histologic grading compared with subclassification of papillary thyroid carcinoma. Cancer 88 1902-1908. (doi:10.1002/(SICI)1097-0142(20000415)88:8< 1902::AID-CNCR20 > 3.0.CO;2-Y)

Baloch ZW \& LiVolsi VA 2006 Microcarcinoma of the thyroid. Advances in Anatomic Pathology 13 69-75. (doi:10.1097/01.pap.0000213006. 10362.17)

Barbaro D, Incensati RM, Materazzi G, Boni G, Grosso M, Panicucci E, Lapi P, Pasquini C \& Miccoli P 2014 The BRAF V600E mutation in papillary thyroid cancer with positive or suspected pre-surgical cytological finding is not associated with advanced stages or worse prognosis. Endocrine 45 462-468. (doi:10.1007/s12020-013-0029-5)

Beninato T, Scognamiglio T, Kleiman DA, Uccelli A, Vaca D, Fahey TJ III \& Zarnegar R 2013 Ten percent tall cells confer the aggressive features of the tall cell variant of papillary thyroid carcinoma. Surgery $\mathbf{1 5 4}$ 1331-1336; discussion 1336. (doi:10.1016/j.surg.2013.05.009)

Boos LA, Dettmer M, Schmitt A, Rudolph T, Steinert H, Moch H, SobrinhoSimoes M, Komminoth P \& Perren A 2013 Diagnostic and prognostic implications of the PAX8-PPAR $\gamma$ translocation in thyroid carcinomas-a TMA-based study of 226 cases. Histopathology 63 234-241. (doi:10.1111/his.12150)

Cancer Genome Atlas Research N 2014 Integrated genomic characterization of papillary thyroid carcinoma. Cell 159 676-690. (doi:10.1016/ j.cell.2014.09.050)

Cheng S, Serra S, Mercado M, Ezzat S \& Asa SL 2011 A high-throughput proteomic approach provides distinct signatures for thyroid cancer behavior. Clinical Cancer Research 15 2385-2394. (doi:10.1158/ 1078-0432.CCR-10-2837)

DeLellis R, Lloyd R, Heitz P \& Eng C. 2004 World Health Organization classification of tumours. In Pathology and Genetics of Tumours of Endocrine Organs. Lyon, France: IARC Press.

Dettmer M, Schmitt A, Steinert H, Haldemann A, Meili A, Moch H, Komminoth P \& Perren A 2011 Poorly differentiated thyroid carcinomas: how much poorly differentiated is needed? American Journal of Surgical Pathology 35 1866-1872. (doi:10.1097/PAS. Ob013e31822cf962)

Dettmer M, Schmitt A, Steinert H, Moch H, Komminoth P \& Perren A 2012 Poorly differentiated oncocytic thyroid carcinoma-diagnostic implications and outcome. Histopathology 60 1045-1051. (doi:10.1111/j. 1365-2559.2012.04188.x)

Elisei R, Viola D, Torregrossa L, Giannini R, Romei C, Ugolini C, Molinaro E, Agate L, Biagini A, Lupi C et al. 2012 The BRAF(V600E) mutation is an independent, poor prognostic factor for the outcome of patients with low-risk intrathyroid papillary thyroid carcinoma: single-institution results from a large cohort study. Journal of Clinical Endocrinology and Metabolism 97 4390-4398. (doi:10.1210/jc.2012-1775)

Eloy C, Santos J, Soares P \& Sobrinho-Simoes M 2011 The preeminence of growth pattern and invasiveness and the limited influence of BRAF and RAS mutations in the occurrence of papillary thyroid carcinoma lymph node metastases. Virchows Archiv 459 265-276. (doi:10.1007/ s00428-011-1133-7)

Ganly I, Ibrahimpasic T, Rivera M, Nixon I, Palmer FL, Patel SG, Tuttle RMM, Shah JP \& Ghossein RM 2013 Prognostic Implications of papillary thyroid carcinoma with tall cell features. Thyroid 24 662-670. (doi:10.1089/thy.2013.0503)

Ghossein R \& Livolsi VA 2008 Papillary thyroid carcinoma tall cell variant. Thyroid 18 1179-1181. (doi:10.1089/thy.2008.0164)
Guerra A, Sapio MR, Marotta V, Campanile E, Rossi S, Forno I, Fugazzola L, Budillon A, Moccia T, Fenzi G et al. 2012a The primary occurrence of $\mathrm{BRAF}(\mathrm{V} 600 \mathrm{E})$ is a rare clonal event in papillary thyroid carcinoma. Journal of Clinical Endocrinology and Metabolism 97 517-524. (doi:10.1210/jc.2011-0618)

Guerra A, Fugazzola L, Marotta V, Cirillo M, Rossi S, Cirello V, Forno I, Moccia T, Budillon A \& Vitale M 2012b A high percentage of BRAF V600E alleles in papillary thyroid carcinoma predicts a poorer outcome. Journal of Clinical Endocrinology and Metabolism 97 2333-2340. (doi:10.1210/jc.2011-3106)

Handkiewicz-Junak D, Czarniecka A \& Jarzab B 2010 Molecular prognostic markers in papillary and follicular thyroid cancer: current status and future directions. Molecular and Cellular Endocrinology 322 8-28. (doi:10.1016/j.mce.2010.01.007)

Huang FW, Hodis E, Xu MJ, Kryukov GV, Chin L \& Garraway LA 2013 Highly recurrent TERT promoter mutations in human melanoma. Science 339 957-959. (doi:10.1126/science.1229259)

Ito Y, Yoshida $\mathrm{H}$, Maruo R, Morita S, Takano T, Hirokawa M, Yabuta T, Fukushima M, Inoue $\mathrm{H}$, Tomoda $\mathrm{C}$ et al. 2009 BRAF mutation in papillary thyroid carcinoma in a Japanese population: its lack of correlation with high-risk clinicopathological features and disease-free survival of patients. Endocrine Journal 56 89-97. (doi:10.1507/ endocrj.K08E-208)

Kim TH, Park YJ, Lim JA, Ahn HY, Lee EK, Lee YJ, Kim KW, Hahn SK, Youn YK, Kim KH et al. 2012 The association of the BRAF(V600E) mutation with prognostic factors and poor clinical outcome in papillary thyroid cancer: a meta-analysis. Cancer 118 1764-1773. (doi:10.1002/ cncr.26500)

Koperek O, Kornauth C, Capper D, Berghoff AS, Asari R, Niederle B, von Deimling A, Birner P \& Preusser M 2012 Immunohistochemical detection of the BRAF V600E-mutated protein in papillary thyroid carcinoma. American Journal of Surgical Pathology 36 844-850. (doi:10.1097/PAS.0b013e318246b527)

Landa I, Ganly I, Chan TA, Mitsutake N, Matsuse M, Ibrahimpasic T, Ghossein RA \& Fagin JA 2013 Frequent somatic TERT promoter mutations in thyroid cancer: higher prevalence in advanced forms of the disease. Journal of Clinical Endocrinology and Metabolism 98 E1562-E1566. (doi:10.1210/jc.2013-2383)

Li C, Lee KC, Schneider EB \& Zeiger MA 2012 BRAF V600E mutation and Its association with clinicopathological features of papillary thyroid cancer: a meta-analysis. Journal of Clinical Endocrinology 97 4559-4970. (doi:10.1210/jc.2012-2104)

Liu T, Wang N, Cao J, Sofiadis A, Dinets A, Zedenius J, Larsson C \& Xu D $2013 a$ The age- and shorter telomere-dependent TERT promoter mutation in follicular thyroid cell-derived carcinomas. Oncogene 33 4978-4984. (doi:10.1038/onc.2013.446)

Liu X, Bishop J, Shan Y, Pai S, Liu D, Murugan AK, Sun H, El-Naggar A \& Xing M 2013 $b$ Highly prevalent TERT promoter mutations in aggressive thyroid cancers. Endocrine-Related Cancer 20 603-610. (doi:10.1530/ ERC-13-0210)

LiVolsi VA 2010 Papillary carcinoma tall cell variant (TCV): a review. Endocrine Pathology 21 12-15. (doi:10.1007/s12022-010-9106-y)

Melo M, da Rocha AG, Vinagre J, Batista R, Peixoto J, Tavares C, Celestino R, Almeida A, Salgado C, Eloy C et al. 2014 TERT promoter mutations are a major indicator of poor outcome in differentiated thyroid carcinomas. Journal of Clinical Endocrinology and Metabolism 99 E754-E765. (doi:10.1210/jc.2013-3734)

Nikiforov YEB, Paul W \& Thompson LD 2012 Diagnostic Pathology and Molecular Genetics of the Thyroid: A Comprehensive Guide for Practicing Thyroid Pathology. Baltimore, MD, USA: Lippincott Williams \& Wilkins (LWW).

Nikiforova MN, Kimura ET, Gandhi M, Biddinger PW, Knauf JA, Basolo F, Zhu Z, Giannini R, Salvatore G, Fusco A et al. 2003 BRAF mutations in thyroid tumors are restricted to papillary carcinomas and anaplastic or poorly differentiated carcinomas arising from papillary carcinomas.

Published by Bioscientifica Ltd. 
Journal of Clinical Endocrinology and Metabolism 88 5399-5404. (doi:10.1210/jc.2003-030838)

Ostrowski ML \& Merino MJ 1996 Tall cell variant of papillary thyroid carcinoma: a reassessment and immunohistochemical study with comparison to the usual type of papillary carcinoma of the thyroid. American Journal of Surgical Pathology 20 964-974. (doi:10.1097/ 00000478-199608000-00005)

Sancisi V, Nicoli D, Ragazzi M, Piana S \& Ciarrocchi A 2012 BRAF V600E mutation does not mean distant metastasis in thyroid papillary carcinomas. Journal of Clinical Endocrinology and Metabolism 97 E1745-E1749. (doi:10.1210/jc.2012-1526)

Schlumberger MJ 1998 Papillary and follicular thyroid carcinoma. New England Journal of Medicine 338 297-306. (doi:10.1056/ NEJM199801293380506)

Shimamura M, Nagayama Y, Matsuse M, Yamashita S \& Mitsutake N 2014 Analysis of multiple markers for cancer stem-like cells in human thyroid carcinoma cell lines. Endocrine Journal 61 481-490. (doi:10.1507/endocrj.EJ13-0526)

Sobin S, Gospodarowicz M \& Wittekind C 2009 TNM Classification of Malignant Tumors. 7th Edn. Hoboken, NJ, USA: Wiley-Blackwell.

Sobrinho-Simoes M, Sambade C, Nesland JM \& Johannessen JV 1989 Tall cell papillary carcinoma. American Journal of Surgical Pathology 13 79-80. (doi:10.1097/00000478-198901000-00014)
Statistics Do 2011 Department of Statistics Statistisches Amt des Kantons Zürich. Zürich, Switzerland: Statistisches Amt. (available at: http://www.statistik.zh.ch/internet/justiz_inneres/ statistik/de/home.html)

Vinagre J, Almeida A, Populo H, Batista R, Lyra J, Pinto V, Coelho R, Celestino R, Prazeres H, Lima L et al. 2013 Frequency of TERT promoter mutations in human cancers. Nature Communications 42185 (doi:10.1038/ncomms3185)

Volante M, Collini P, Nikiforov YE, Sakamoto A, Kakudo K, Katoh R, Lloyd RV, LiVolsi VA, Papotti M, Sobrinho-Simoes M et al. 2007 Poorly differentiated thyroid carcinoma: the Turin proposal for the use of uniform diagnostic criteria and an algorithmic diagnostic approach. American Journal of Surgical Pathology 31 1256-1264. (doi:10.1097/PAS. Ob013e3180309e6a)

Xing M, Alzahrani AS, Carson KA, Viola D, Elisei R, Bendlova B, Yip L, Mian C, Vianello F, Tuttle RM et al. 2013 Association between BRAF V600E mutation and mortality in patients with papillary thyroid cancer. Journal of the American Medical Association 309 1493-1501. (doi:10.1001/jama.2013.3190)

Yachida S, Jones S, Bozic I, Antal T, Leary R, Fu B, Kamiyama M, Hruban RH, Eshleman JR, Nowak MA et al. 2010 Distant metastasis occurs late during the genetic evolution of pancreatic cancer. Nature $\mathbf{4 6 7}$ 1114-1117. (doi:10.1038/nature09515)

Received in final form 2 April 2015

Accepted 10 April 2015

Made available online as an Accepted Preprint

13 April 2015
(C) 2015 Society for Endocrinology Printed in Great Britain
Published by Bioscientifica Ltd. 